\title{
THE APPLICATION OF E-TECHNOLOGY FOR MARINE INFORMATION SERVICE
}

\author{
Lien-Kwei Chien \\ Department of Harbor and River Engineering, National Taiwan Ocean University, Keelung, Taiwan, R.O.C \\ Tsung-Shen Feng \\ Department of Harbor and River Engineering, National Taiwan Ocean University, Keelung, Taiwan, R.O.C., \\ D91520004@mail.ntou.edu.tw \\ Chieh-Cheng Yen \\ Energy and Environment Research Laboratories, Industrial Technology Research Institute, Taiwan, R.O.C \\ Beng-Chun Lee \\ Department of Environmental and Hazards-Resistant Design, Huafan University, Taipei, Taiwan, R.O.C \\ Heng-Wen Chang \\ Energy and Environment Research Laboratories, Industrial Technology Research Institute, Taiwan, R.O.C
}

Follow this and additional works at: https://jmstt.ntou.edu.tw/journal

Part of the Civil and Environmental Engineering Commons

\section{Recommended Citation}

Chien, Lien-Kwei; Feng, Tsung-Shen; Yen, Chieh-Cheng; Lee, Beng-Chun; and Chang, Heng-Wen (2010) "THE APPLICATION OF e-TECHNOLOGY FOR MARINE INFORMATION SERVICE," Journal of Marine Science and Technology. Vol. 18: Iss. 6, Article 3.

DOI: $10.51400 / 2709-6998.1937$

Available at: https://jmstt.ntou.edu.tw/journal/vol18/iss6/3

This Research Article is brought to you for free and open access by Journal of Marine Science and Technology. It has been accepted for inclusion in Journal of Marine Science and Technology by an authorized editor of Journal of Marine Science and Technology. 


\section{THE APPLICATION OF e-TECHNOLOGY FOR MARINE INFORMATION SERVICE}

Acknowledgements

This research was supported by the TAIWAN Central Weather Bureau. Grateful appreciation is expressed to their support: MOTC-CWB-98-0-02. 


\title{
THE APPLICATION OF Q-TECHNOLOGY FOR MARINE INFORMATION SERVICE
}

\author{
Lien-Kwei Chien*, Tsung-Shen Feng*, Chieh-Cheng Yen**, \\ Beng-Chun Lee***, and Heng-Wen Chang**
}

\begin{abstract}
Key words: subjects tendency technology, cluster and return period analysis, marine drifter track analysis, Global Satellite Tracking Web GIS, Location-Based Service.
\end{abstract}

\begin{abstract}
The purpose of this study is to establish the multi-function querying system by applying e-technology in marine data. Subjects tendency technology is new concept in system designing process of this study which originate from simulation language that was replace the structural technology. We also investigate the statistical characteristics of ocean waves and surges over Taiwan waters by cluster and return period analysis. Marine drifter track analysis and search area determination system were also analysis and import to GIS querying system. In order to make the locations of the near shore ships and sailing data could be easily convey through wireless communication and import to databases, the Global Satellite Tracking Web GIS was established in this study. The ships locations and real time marine data were obtained in computer through internet browser. The efficiency of marine information system could predict the true marine conditions in coastal area and provide useful rescue information in the future.
\end{abstract}

\section{INTRODUCTION}

With the increasing influence of global warming, the amounts of typhoon attacked Taiwan were increased apparently. The main reason of sea level rising shapely in coastal area were storm wave correspond to typhoon and low-pressure. Furthermore the impact of Taiwan coastal environment due to these phenomenons of inundation by the sea, crop damage, coastal erosion and serious flood were all caused by storm waves. The efficiency of a search and rescue operation could be improved by predicting the true marine conditions in coastal area and

Paper submitted 07/30/09; revised 12/25/09; accepted 02/02/10. Author for correspondence: Tsung-Shen Feng (e-mail: D91520004@mail.ntou.edu.tw). *Department of Harbor and River Engineering, National Taiwan Ocean University, Keelung, Taiwan, R.O.C.

**Energy and Environment Research Laboratories, Industrial Technology Research Institute, Taiwan, R.O.C.

***Department of Environmental and Hazards-Resistant Design, Huafan University, Taipei, Taiwan, R.O.C. developing a marine information system. Therefore, how to apply the e-technology in marine data and establish the multifunction querying system was the main purpose of this study.

The study adopted e-technology to establish the querying system which apply the function of overall marine information and refer to the results of marine GIS information service system Chien et al. 2009 [4]. In order to achieve the purpose of this study, the overall planning of marine e-technology information system, the Statistical Characteristics for Waves and Surges over Taiwan Waters by return period analysis, and drift orbit oversea and rescue range analysis were discussed in this study. The other processes of this study were converting the disaster protection model into a computer system and including into the marine information system.

Related applications of marine GIS studied after that time in Taiwan, includes the studied results of storm module with GIS by the Industrial Technology Research Institute [8], the GPS and GIS applied in fishery planning at coastal area [18], the planning study of the marine monitoring and ocean environment database (Chinese Ocean Underwater Technology Association, COUTA, 1994) [5], the study of spatial exploitation planning system [20], and the possibility of establishment for marine GIS in national park [12], the establishment of water depth investigation for coastal area and environment database under sea [6], the establishment of geographical information database in harbor area and coastal room [17], the study of establishment for artificial structure [13] and the establishment of coastal tourism safety information and monitoring system [7].

The marine GIS information system was established by using ArcIMS system with marine database which could provide marine climate, water depth, harbor layout, bottom geology, ocean protection area, navigational markers, seabed pipeline, Three Dimensional Environment Querying System, Notice to Mariners Information System and Global Satellite Vessels Tracking Web System [4, 21].

\section{MARINE E-TECHNOLOGY AND SYSTEM STRUCTURE}

\section{Development of Marine Information Database}

The study apply appropriate analytic method to establish 


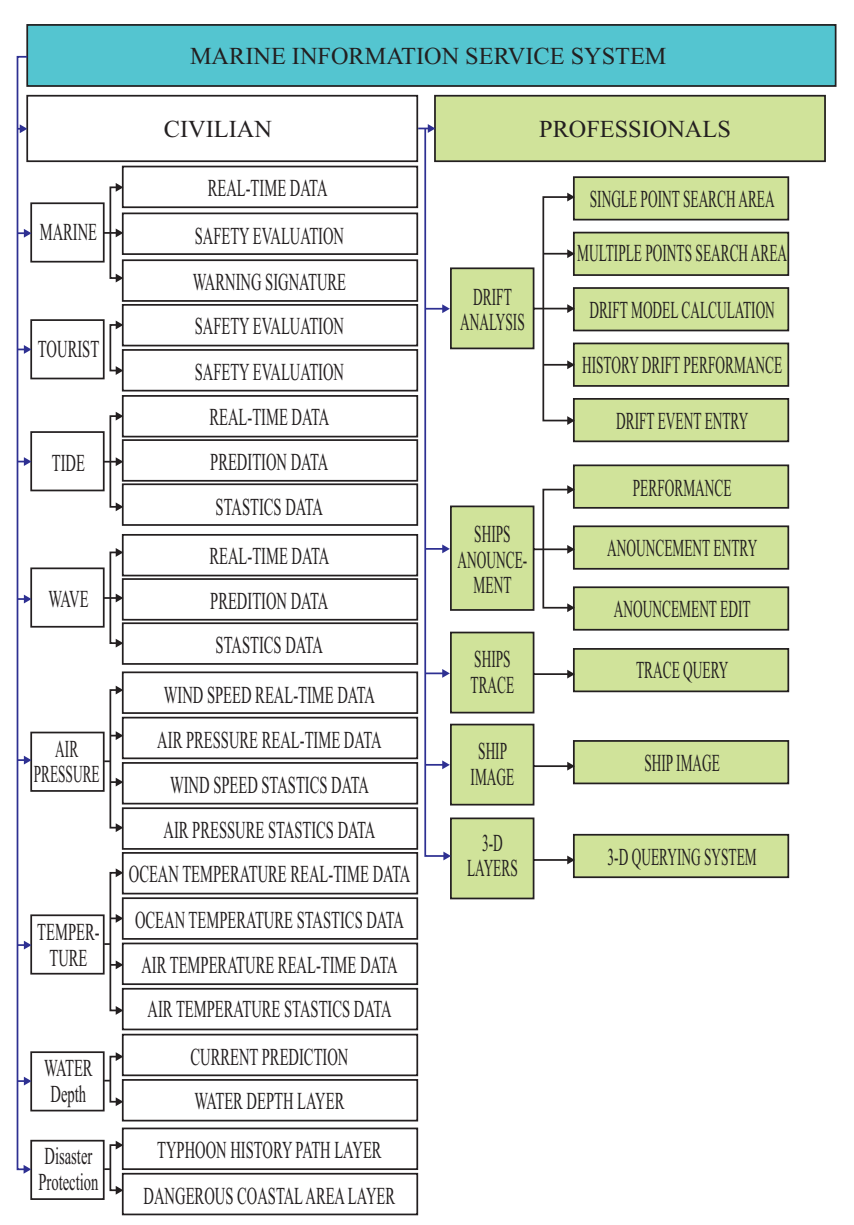

Fig. 1. Gradation framework figures on GIS.

the marine database and system model which according to the study process and information provided by Central Weather Bureau (CWB). Querying system planned in this study not only consider the requirement of user to design complete items but refer the present study including the Central Weather Bureau internet, marine GIS information service system and Taiwan marine security information system. And the advantage of querying system is supply the friendly interface by organizing the geographic service and disaster base which differ from other internet service. Users could obtain diversification information and many kinds of marine service in this internet through gradation framework figures which as shown in Fig. 1. There are eight types of marine data including immediately marine condition, tourist activities, tide, wave, wind, temperature, application of GIS and disaster protection.

Familiar data were collected to same group for the planning of GIS database at first step. And different figure element record divided by data spatial performance. Point, line and area or polygon were classified in earlier, but grid, TIN, multifeatures were classified GIS database presently. As a result, each figures in this GIS database were separated into the format of "layers" which as shown in Fig. 2.

The internet operation is the main working stage of the

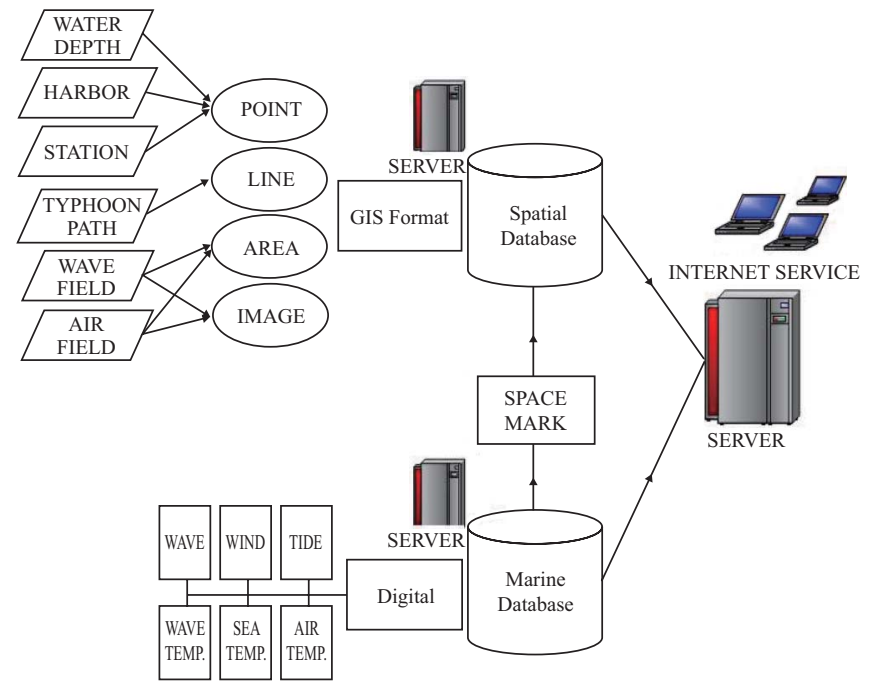

Fig. 2. Data layers on GIS database.

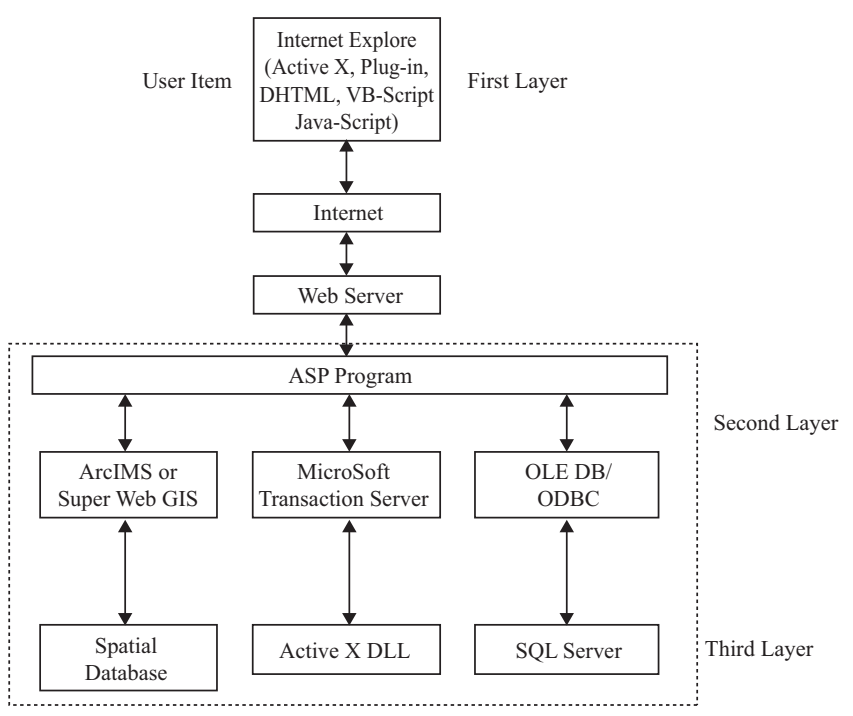

Fig. 3. Framework of database system.

marine GIS information service system. Earlier operation methods of system establishment is dispersive framework, most of them were two-layer Client-Server framework. The Server item was responsible for handling, saving and managing, and other are responsible for interface handing and logic calculation by the Client item. From these methods, the system only achieves the data sharing function, and each system had to revise in Client item. With the population of internet and development of dispersive framework, the study planned the three-layer frameworks to establish the system, and the framework opinion was two tier increased to three tier even multitier. Therefore, database, logic calculation and user interface working in fitting system respectively. Multi-tier function not only could share the data even logic calculation but achieve the purpose of dispersive and resource sharing, the three layer framework as shown in Fig. 3. 


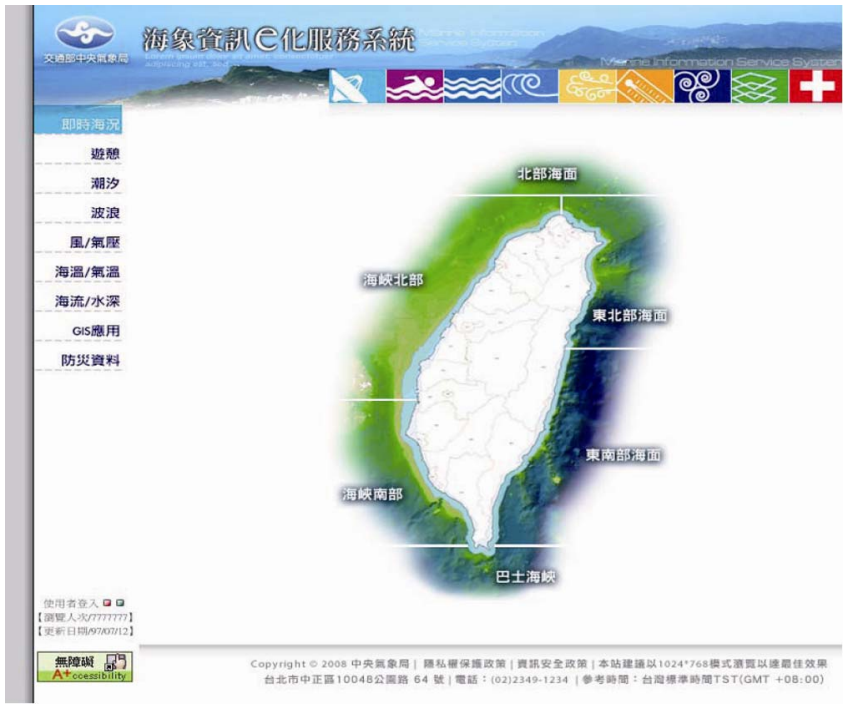

Fig. 4. The performance of marine information system (1).

\section{2. e-Technology and Model of Marine Information System}

Firstly, the marine related data were classified according to the types in this study, and subdivide to useful predicted historic and statistic information which can make users query marine information rapidly.

Subjects tendency technology is a new concept in system designing process which originate from simulation language that was replace the structural technology gradually. The system described by object module with the concept of packaging and inheriting data into object system exploitation. Unified Modeling Language (UML) is a kind of subjects' tendency technology tool which described system with many figures and adopted version by Object Management Group (OMG) is UML 1.1. The version depends on the system requirement to produce figures including the objective, order, individual, coordinated, conditional, classified, and movable figures. The study adopted UML 1.1 as the model language and applied subjects' tendency to analyze and design system. Information products in this study include individual and classified figures.

Moreover, the study also transfers marine data into different types of management information according to the performance of spatial analysis in geographical information system which could offer the reference of development in GIS application. The users could store useful data effectively by applying marine database and acting rapidly when facing the unusual conditions. Meanwhile, marine information system also collected present geographic data and provided data management and interchange service. The performance of Marine Information Service System was shown in Figs. 4 and 5.

\section{STASTISTICAL CHARACTERISTIC OF WAVES AND SURGES OVER TAIWAN WATER REGIONS}

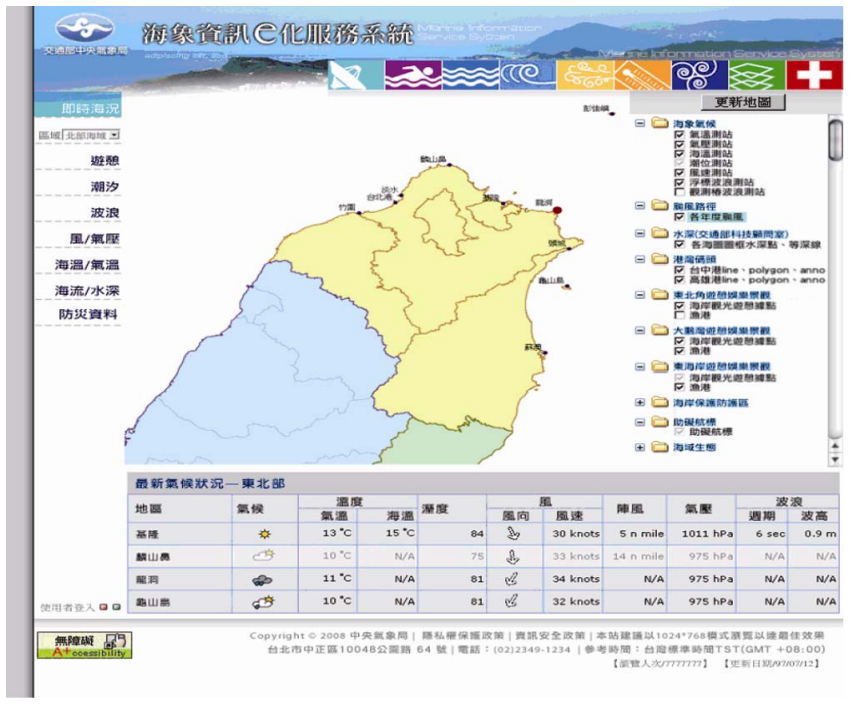

Fig. 5. The performance of marine information system (2).

Ocean waves and surges have attracted considerable attentions throughout history. The mechanism of wave and surge is still not fully understood in the present day. Statistical analysis of the wave and surge data is a quite popular and practical way to understand the characteristics of these ocean phenomena. It is also possible to predict the sea states by some statistical methods [11, 14, 19].

Measurement always plays an important role on evaluating and describing wave and surge phenomena and characteristics. Since 1998, the government organizations in Taiwan have established a coastal monitoring network around Taiwan coast. The coastal monitoring network was jointly established by CWB Water Resources Agency and Tourist Bureau [9]. To obtain the surge data, the harmonic analysis is applied to separate the astronomical tide and surge from the water level records around Taiwan. Due to the numerous stations and long-term data over Taiwan waters, it should be possible to understand well the sea state characteristics in this area. We here investigate the statistical features of ocean waves and surges. The cluster and return period analysis, which should be able to derive the spatial features from the whole Taiwan sea area, are applied here to reveal the characteristics of wave height and surge.

Cluster analysis is a common technique for statistical data analysis, which has been used in many fields [10]. Objects in the same cluster are very similar and objects in different clusters are very distinct. We construct clusters from the hierarchical cluster tree. As shown in (1), Euclidean distance $E_{d}$ is applied here to determine the degree of similarity of the records from different stations:

$$
E_{d}=\sqrt{\sum_{i=1}^{N}\left(x_{i}-y_{i}\right)^{2}}
$$

where $x_{i}$ and $y_{i}$ are the wave height or surge data from two 


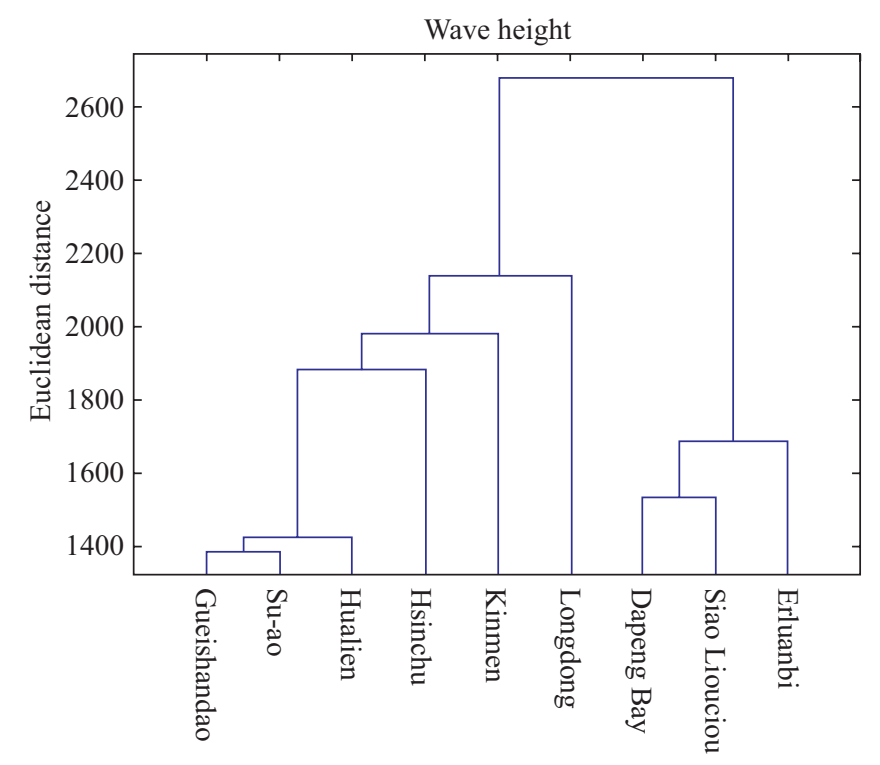

Fig. 6. The hierarchical cluster tree of wave height records.

different stations, $N$ is the total amount of the data set.

In addition to the cluster analysis, return period analysis is also used here. A return period, which is also called recurrence interval, is an estimate of the interval of time between events of certain intensity. It is a statistical measurement denoting the average recurrence interval over an extended period of time, and is usually required in risk analysis. Here we applied the return period to evaluate the risk of ocean waves and surge in different coastal areas around Taiwan. To calculate the return period from the wave height and surge data set, the probability distribution of the data set needs to be determined first. Normal, Rayleigh, Weibull, and Gamma distribution functions are considered to fit the distribution of the wave height and surge data in this study.

\section{Cluster Analysis of Wave Height and Surge}

The cluster analyses of wave height and surge data are discussed in this section. As shown in Fig. 6, the wave records from different stations can be classified into several clusters which are determined by the Euclidean distance. The statistical characteristics of the wave height records from Gueishandao, Su-ao and Hualien are quite similar. The locations among these three stations are near. The wave height records from Longdong are not classified into the same cluster of Gueishandao and Su-ao, even though the location of Longdong station is quite close to them. The location of Longdong buoy is inside of a bay. The sea states should be influenced by topography in this area. It should be the reason the statistical characteristics of wave height records from Longdong station is not similar to neighbor stations.

The hierarchical cluster tree of surge records over Taiwan waters is shown in Fig. 7. It shows the statistical characteristics of surge records among Hualien, Fugang, Lyudao and Shihti stations are similar. All of these four stations are lo-

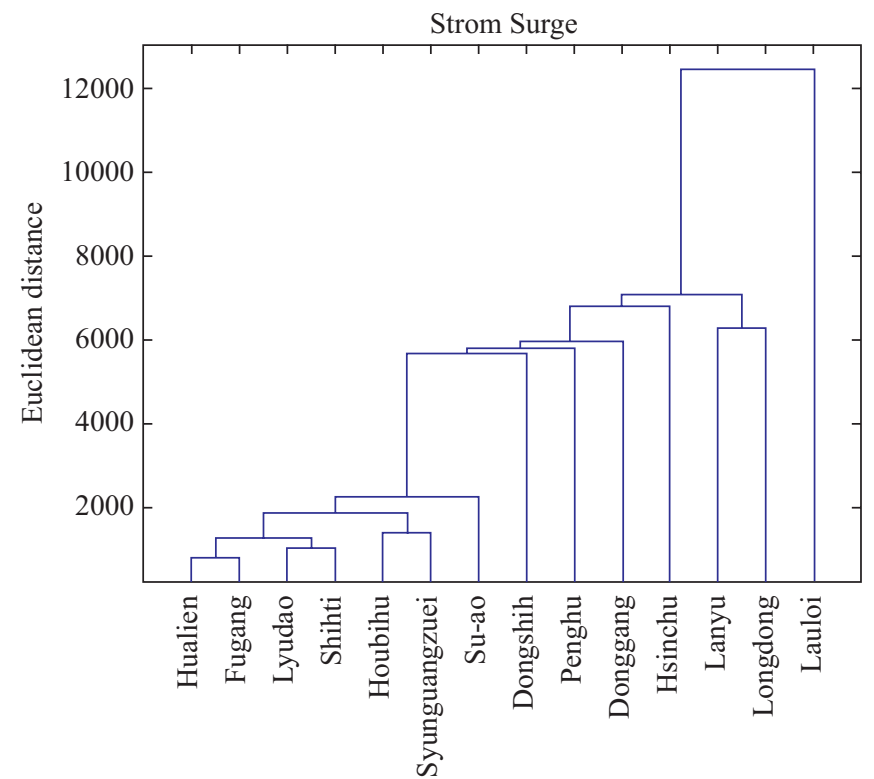

Fig. 7. The hierarchical cluster tree of surge records.

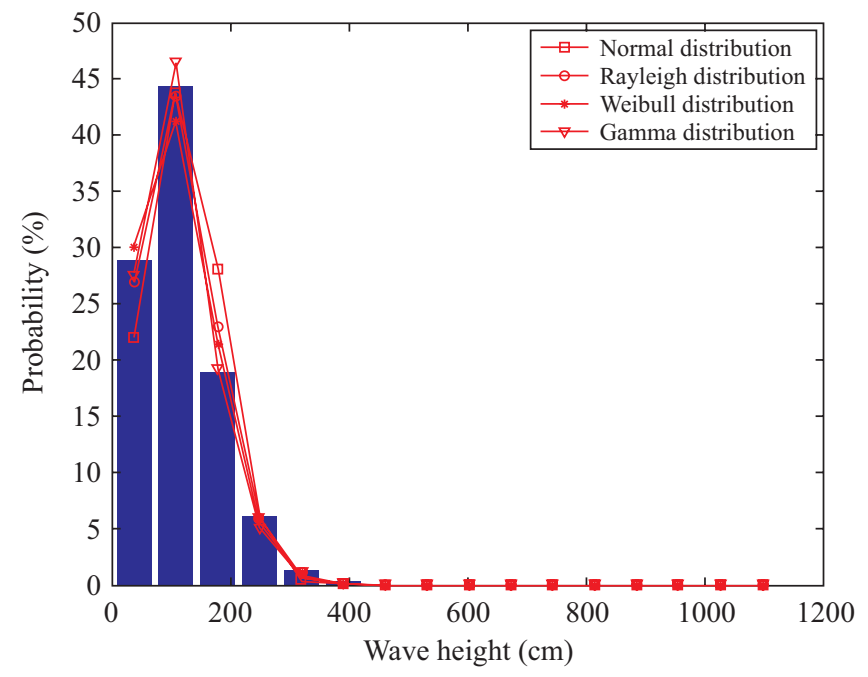

Fig. 8. The probability distributions of the wave height data from Hualien station.

cated in eastern coast of Taiwan. The spatial characteristics inside this area should be similar.

\section{Probability Distribution of Sea States}

The probability distributions of the wave height and surge data are shown in Figs. 8 and 9. Four different probability distribution functions are specified in our study. Due to the limitation of the printed pages, we only present the examples from Hualien wave station and Donggang tide station.

The results of chi-square goodness-of-fit test by different probability distribution functions are shown in Tables 1 and 3 . They show that most of the distribution functions can be accepted by the chi-square goodness-of-fit test. In order to de- 


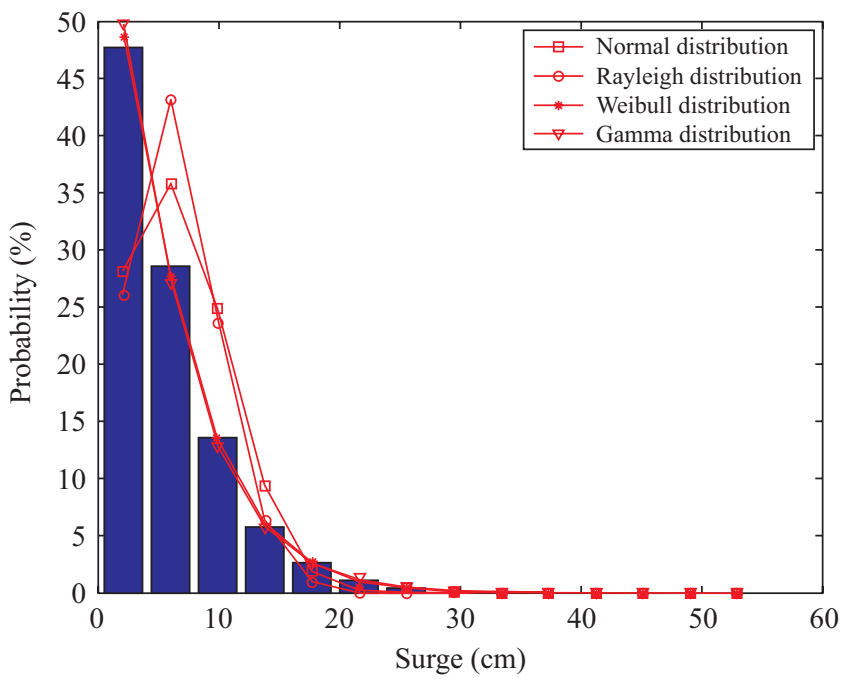

Fig. 9. The probability distributions of the surge data from Donggang station.

Table 1. The chi-square goodness-of-fit test of wave height records.

\begin{tabular}{|l|c|c|c|c|}
\hline & $\begin{array}{c}\text { Normal } \\
\text { distribution }\end{array}$ & $\begin{array}{c}\text { Rayleigh } \\
\text { distribution }\end{array}$ & $\begin{array}{c}\text { Weibull } \\
\text { distribution }\end{array}$ & $\begin{array}{c}\text { Gamma } \\
\text { distribution }\end{array}$ \\
\hline Hualien & $\bigcirc$ & $\bigcirc$ & $\bigcirc$ & $\bigcirc$ \\
\hline Hsinchu & $\times$ & $\bigcirc$ & $\bigcirc$ & $\bigcirc$ \\
\hline Longdong & $\bigcirc$ & $\bigcirc$ & $\bigcirc$ & $\bigcirc$ \\
\hline Gueishandao & $\times$ & $\times$ & $\times$ & $\times$ \\
\hline Dapeng Bay & $\bigcirc$ & $\bigcirc$ & $\bigcirc$ & $\bigcirc$ \\
\hline Siao Liouciou & $\bigcirc$ & $\bigcirc$ & $\bigcirc$ & $\bigcirc$ \\
\hline Erluanbi & $\bigcirc$ & $\bigcirc$ & $\bigcirc$ & $\bigcirc$ \\
\hline Kinmen & $\bigcirc$ & $\bigcirc$ & $\bigcirc$ & $\bigcirc$ \\
\hline Su-ao & $\bigcirc$ & $\bigcirc$ & $\bigcirc$ & $\bigcirc$ \\
\hline
\end{tabular}

$\bigcirc$ : Accept the hypothesis $\quad \times$ : Reject the hypothesis

Table 2. The root mean square error of wave height data by different probability distributions.

\begin{tabular}{|l|c|c|c|c|}
\hline & $\begin{array}{c}\text { Normal } \\
\text { distribution }\end{array}$ & $\begin{array}{c}\text { Rayleigh } \\
\text { distribution }\end{array}$ & $\begin{array}{c}\text { Weibull } \\
\text { distribution }\end{array}$ & $\begin{array}{c}\text { Gamma } \\
\text { distribution }\end{array}$ \\
\hline Hualien & 0.0164 & 0.0068 & 0.0060 & 0.0038 \\
\hline Hsinchu & 0.0184 & 0.0081 & 0.0030 & 0.0024 \\
\hline Longdong & 0.0231 & 0.0183 & 0.0065 & 0.0072 \\
\hline Gueishandao & 0.0022 & 0.0051 & 0.0025 & 0.0098 \\
\hline Dapeng Bay & 0.0470 & 0.0403 & 0.0249 & 0.0199 \\
\hline Siao Liouciou & 0.0331 & 0.0259 & 0.0133 & 0.0087 \\
\hline Erluanbi & 0.0271 & 0.0168 & 0.0099 & 0.0054 \\
\hline Kinmen & 0.0233 & 0.0120 & 0.0072 & 0.0055 \\
\hline Su-ao & 0.0189 & 0.0020 & 0.0010 & 0.0036 \\
\hline
\end{tabular}

termine the most suitable distribution functions in different sea areas, we use the root mean square error to calculate the difference between the sea state distribution and the theory dis-
Table 3. The chi-square goodness-of-fit test of surge records.

\begin{tabular}{|l|c|c|c|c|}
\hline & $\begin{array}{c}\text { Normal } \\
\text { distribution }\end{array}$ & $\begin{array}{c}\text { Rayleigh } \\
\text { distribution }\end{array}$ & $\begin{array}{c}\text { Weibull } \\
\text { distribution }\end{array}$ & $\begin{array}{c}\text { Gamma } \\
\text { distribution }\end{array}$ \\
\hline Donggang & $\bigcirc$ & $\bigcirc$ & $\bigcirc$ & $\bigcirc$ \\
\hline Dongshih & $\bigcirc$ & $\bigcirc$ & $\bigcirc$ & $\bigcirc$ \\
\hline Houbihu & $\bigcirc$ & $\bigcirc$ & $\bigcirc$ & $\bigcirc$ \\
\hline Hsinchu & $\bigcirc$ & $\bigcirc$ & $\bigcirc$ & $\bigcirc$ \\
\hline Hualien & $\bigcirc$ & $\bigcirc$ & $\bigcirc$ & $\bigcirc$ \\
\hline Lanyu & $\bigcirc$ & $\bigcirc$ & $\bigcirc$ & $\bigcirc$ \\
\hline Longdong & $\bigcirc$ & $\bigcirc$ & $\times$ & $\times$ \\
\hline Penghu & $\bigcirc$ & $\bigcirc$ & $\bigcirc$ & $\bigcirc$ \\
\hline Su-ao & $\times$ & $\bigcirc$ & $\bigcirc$ & $\bigcirc$ \\
\hline Syunguangzuei & $\bigcirc$ & $\bigcirc$ & $\bigcirc$ & $\bigcirc$ \\
\hline Shihti & $\bigcirc$ & $\bigcirc$ & $\bigcirc$ & $\bigcirc$ \\
\hline Dawu & $\times$ & $\bigcirc$ & $\bigcirc$ & $\bigcirc$ \\
\hline Lyudao & $\times$ & $\bigcirc$ & $\bigcirc$ & $\bigcirc$ \\
\hline Yong-an & $\bigcirc$ & $\bigcirc$ & $\bigcirc$ & $\bigcirc$ \\
\hline Lauloi & $\bigcirc$ & $\bigcirc$ & $\bigcirc$ & $\bigcirc$ \\
\hline Shueitou & $\bigcirc$ & $\bigcirc$ & $\bigcirc$ & $\bigcirc$ \\
\hline
\end{tabular}

$\bigcirc$ : Accept the hypothesis $\times$ : Reject the hypothesis

Table 4. The root mean square error of surge data by different probability distributions.

\begin{tabular}{|l|c|c|c|c|}
\hline & $\begin{array}{c}\text { Normal } \\
\text { distribution }\end{array}$ & $\begin{array}{c}\text { Rayleigh } \\
\text { distribution }\end{array}$ & $\begin{array}{c}\text { Weibull } \\
\text { distribution }\end{array}$ & $\begin{array}{c}\text { Gamma } \\
\text { distribution }\end{array}$ \\
\hline Donggang & 0.0404 & 0.0491 & 0.0058 & 0.0054 \\
\hline Dongshih & 0.0352 & 0.0433 & 0.0036 & 0.0041 \\
\hline Houbihu & 0.0340 & 0.0377 & 0.0053 & 0.0070 \\
\hline Hsinchu & 0.0242 & 0.0275 & 0.0086 & 0.0111 \\
\hline Hualien & 0.0256 & 0.0313 & 0.0065 & 0.0091 \\
\hline Lanyu & 0.0239 & 0.0294 & 0.0046 & 0.0070 \\
\hline Longdong & 0.0310 & 0.0356 & 0.0041 & 0.0063 \\
\hline Penghu & 0.0336 & 0.0406 & 0.0043 & 0.0047 \\
\hline Su-ao & 0.0396 & 0.0342 & 0.0019 & 0.0007 \\
\hline Syunguangzuei & 0.0029 & 0.0033 & 0.0006 & 0.0009 \\
\hline Shihti & 0.0037 & 0.0037 & 0.0004 & 0.0005 \\
\hline Dawu & 0.0037 & 0.0037 & 0.0003 & 0.0004 \\
\hline Lyudao & 0.0030 & 0.0035 & 0.0004 & 0.0007 \\
\hline Yong-an & 0.0032 & 0.0037 & 0.0004 & 0.0007 \\
\hline Lauloi & 0.0034 & 0.0043 & 0.0001 & 0.0001 \\
\hline Shueitou & 0.0037 & 0.0046 & 0.0002 & 0.0001 \\
\hline
\end{tabular}

tribution functions. As shown in Tables 2 and 4, we determine the suitable distribution function by the minimum value of root mean square error. It is revealed the Gamma distribution function is suitable for describing the probability distribution of the wave height records in most of the sea areas over Taiwan waters. In addition, the Weibull distribution function is suitable for describing the probability distribution of the surge records in most of the sea areas. 
Table 5. The wave height results of 50-year return period.

\begin{tabular}{|l|c|c|}
\hline \multicolumn{1}{|c|}{ Station } & $\begin{array}{c}50 \text {-year recurrence interval } \\
\text { of wave height }(\mathrm{cm})\end{array}$ & Sample size \\
\hline Hualien & 827 & 50285 \\
\hline Hsinchu & 734 & 41341 \\
\hline Longdong & 736 & 44163 \\
\hline Gueishandao & 1719 & 29730 \\
\hline Dapeng Bay & 739 & 30806 \\
\hline Siao Liouciou & 739 & 23551 \\
\hline Su-ao & 906 & 27905 \\
\hline Erluanbi & 834 & 29917 \\
\hline Kinmen & 739 & 33028 \\
\hline
\end{tabular}

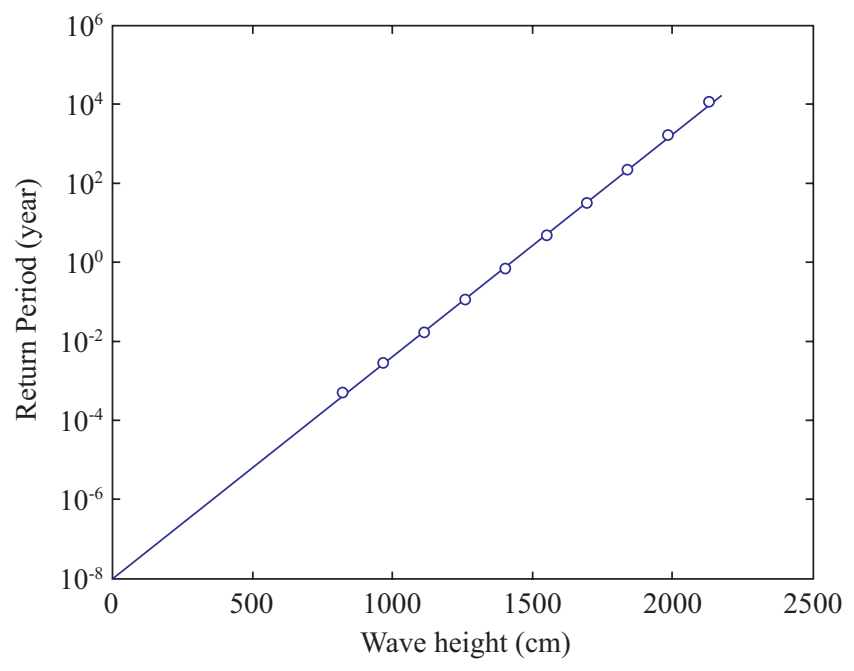

Fig. 10. The return period of the wave height in Gueishandao.

\section{Return Period Analysis of Wave Height}

The extreme wave height and surge of 50-year return period from different areas are shown in Table 5. It shows the wave height results from Gueishandao and $\mathrm{Su}$-ao are quite different. However, the cluster analysis result (Fig. 7) shows that the wave data from Gueishandao and $\mathrm{Su}$-ao can be fall into the same cluster. The inconsistency between the results of cluster analysis and return period analysis should be due to the unsuitable probability distribution function of the wave height data from Gueishandao station. Figure 10 shows return period of the wave height in Gueishandao and Fig. 11 shows the distribution of wave height data from Gueishandao station. Due to the scale of $y$-axis is not clear, we present it in Fig. 12 by the logarithmic type. It shows there are some extreme wave events in Gueishandao sea area, the distribution in this sea area must be influenced by these extreme wave events. Though Table 4 shows Normal distribution is the possible distribution function to describe the wave height characteristic in Gueishandao sea area, there is no distribution functions can be accepted by the chi-square goodness-of-fit test in this area. It leads to the error of the wave height calculation of 50-year return period.

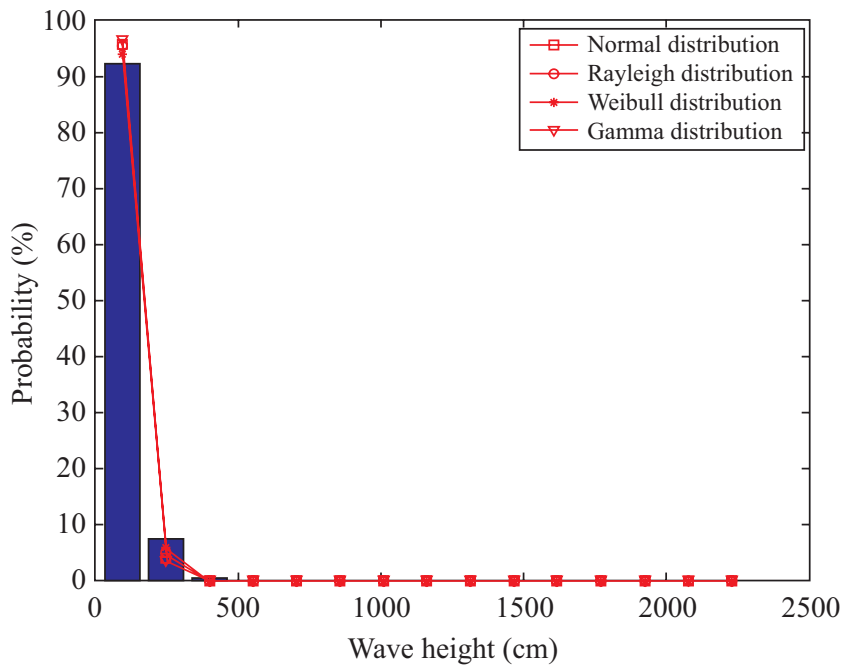

Fig. 11. The probability distributions of the wave height data from Gueishandao station.

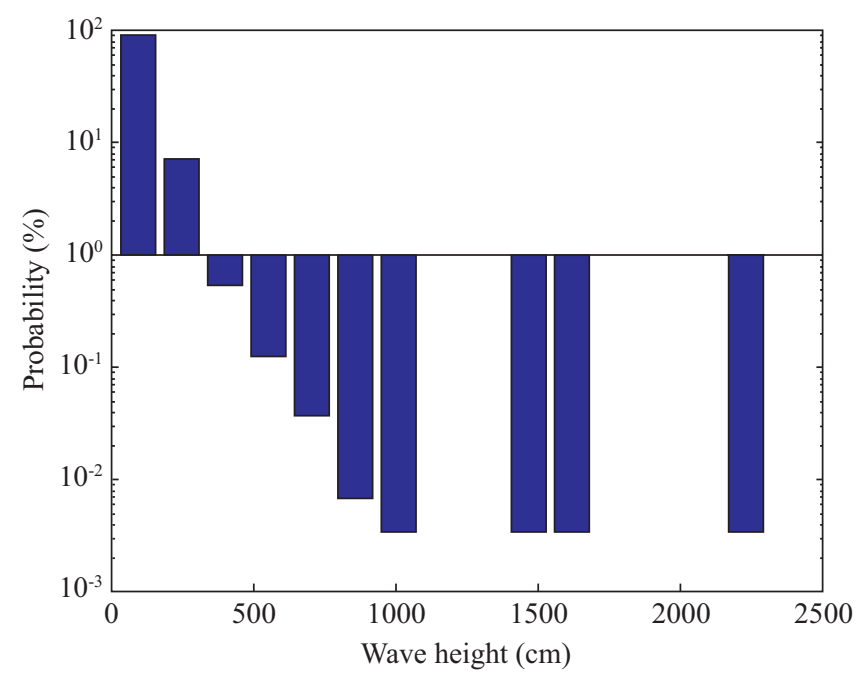

Fig. 12. The probability distributions of the wave height data from Gueishandao station in logarithmic type.

\section{MARINE DRIFTER TRACK ANALYSIS AND SEARCH AREA DETERMINATION (SAD) SYSTEM}

\section{Prediction of Marine Drifter Trajectories}

When the time and position of the distress incident are reported, SAR are conducted based on the information where the drifter will move. Normally the information is coming from the prediction of the drifter trajectories. Aerf [1,2] and Samelson [16] have shown that the prediction of marine drift trajectories is a complex problem, as their Lagrangian motions often display chaotic behavior due to the combination of timerelated and 3D structural motions. In addition, they pointed out that these chaotic non-linear behaviors accelerate the uncertainty of flow fields. Also, when a drifter is subject to 


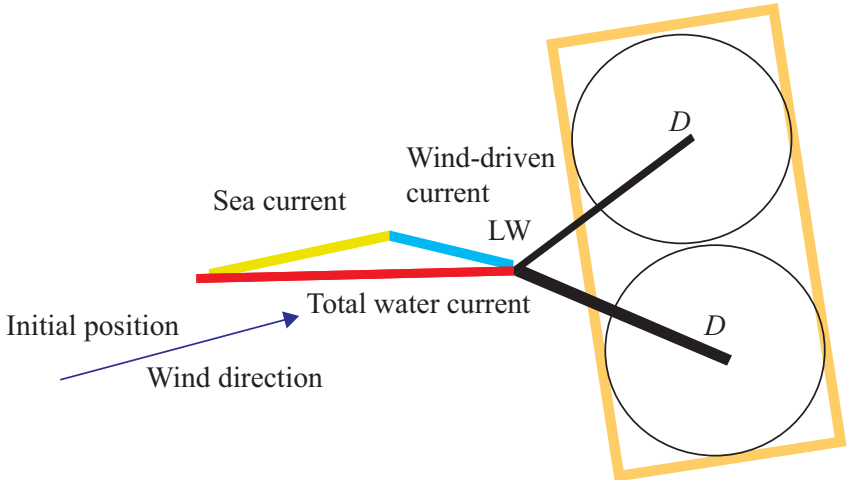

Fig. 13. Schematic illustration of SAD.

winds (leeway effect), its behaviors do not follow its original hydrodynamic mechanism, which creates even more uncertainty in the estimate of drifter trajectories.

There are two ways to predict the trajectory of a drifting object [15] one being the extrapolation from actual measurements, and the other is from the numerical model simulation. The former is subdivided into two methods; one is to estimate the trajectory of a drifter based on historic data, such as surface current speed (vessel drifting, data buoys), surface elevation, meteorological mixing depths or the trajectories that drifting buoys have traveled, and the other is to estimate based on real-time data, such as wind filed, other drifting buoys, surface elevation by satellite (e.g. TOPEX/Poseidon). The latter usually consists of direct calculation of drift trajectories, or calculation of flow fields in Eulerian mesh with the incorporation of other prediction models of Lagrangian drift trajectories. The calculated flow field in Eulerian mesh includes simple models with only few parameters and sophisticated ocean circulation models with consideration of more parameters and higher resolution.

Leeway usually comes from the wind directly blowing against the exposed surfaces of a drifter, and almost all drifters have leeway when subject to wind. Completely submerged objects are assumed to have no leeway. Leeway is often expressed in terms of distance and direction. If a drifter is asymmetric in shape, it will be loaded uneven force from wind, and sometimes causes the divergence of drifter off the downwind direction. The study of leeway started from World War II and there are now many sources of study in this discipline. The data employed in this study come from Leeway Taxonomy, which is proposed by Allen and Plourde [3]. They conducted a review of 26 leeway field studies and provided a systematic approach to classify leeway objects by primary and secondary characteristics that affect their leeway drift. The purpose of taxonomy is to provide a classification system that allows the search planner to identify an appropriate class for the drifting object of interest. Their results provide valuable information to assist in correct application of the most accurate leeway values. Using the measurements of onsite wind speed, wind direction and the characters from leeway tax- onomy, the leeway speed, direction and divergence angle of leeway are determined.

Marine drifter track analysis is established to provide the information of drifter trajectories on the basis of current and wind provided from CWB ocean current model and atmospheric model and updated two times a day. Those models provide forecast data 72 hours ahead and 12 hours hindcast data at update time. It's also easier to modify the current and wind data from other numerical models. In the study, lagrangian trajectory method with time and space bilinear interpolation is used in combination with the leeway of drift to calculate the drifter trajectory. Other methods will be used in the future to account for more detail drift mechanism.

\section{Search Area Determination}

When objects are missing in the marine environment, the $\mathrm{SAD}$ is able to help the search and rescue units (SRUs) to perform the rescue missions in a timely and effective manner. At present, the operation procedures of Coast Guard Administration (CGA) in Taiwan are adopted from those of U.S. Coast Guard for planning of search areas, which are given to local Coast Guard Battalion to perform search and rescue (SAR).

The SAD system of CGA needs several information to determine SAR area, such as sea current and wind driven current at incident position, elapsed time to arrive the position estimated, leeway of object, initial position etc. They try to identify the sea current and wind based on the information collected at the incident location. The wind-driven current is found by looking up the "wind-driven current table". In addition, "correction table for wind-driven currents with Coriolis force" is used for the correction of wind-driven current direction. The total water current is the vector sum of currents affecting the search objects and multiplied by the elapsed time to find the drift distance by current. Considering the leeway effect, the leeway speed is obtained from the leeway taxonomy table, and multiplied by elapsed time to determine the leeway distance. The divergence of leeway gives the angles (positive and negative angle) off wind direction. Therefore, two datum points $(D)$ are obtained from the incident initial position with the vector sum of total water current distance and leeway distance with two divergence angles. Datum point is the location with which the object is most likely to end up. The distance between datum point and initial position is the drift distance. The search radius is the product of drift distance, confidence index and safety factor. The search area is then determined by connecting the tangents of both circles, as shown in Fig. 13.

\section{Comprehensive Analysis of Drifter Trajectory and Search Area Determination}

In this study, the CWB ocean current model with winddriven current is used for the verification of SAD and the calculation of drifter trajectories.

For the SAD provided by CGA, only the steady state hydrologic information at the incident site is considered. There are ten incidents, ten drifter trajectories at Green Island and six 


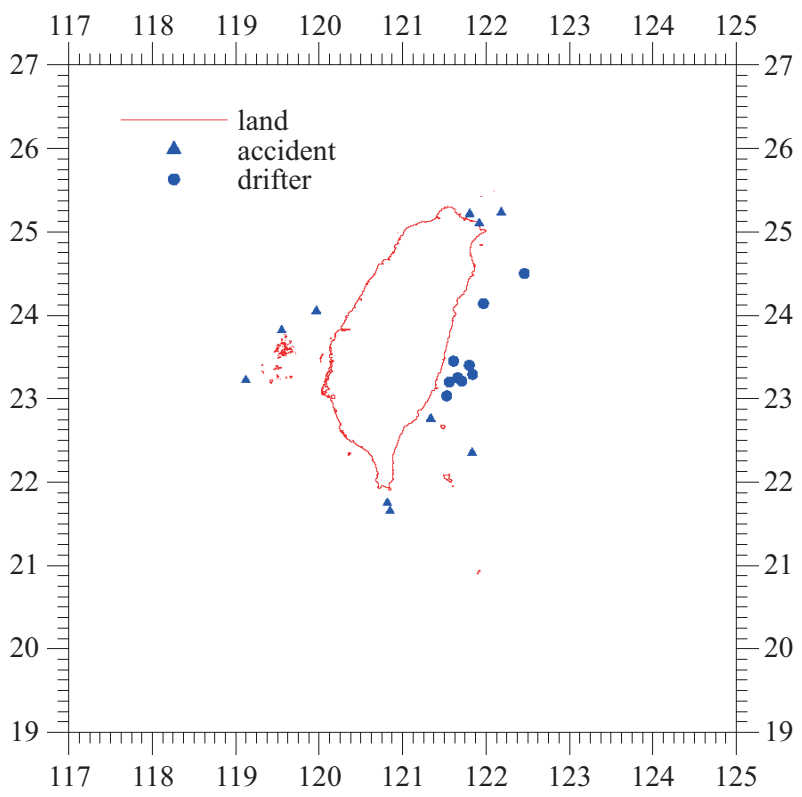

Fig. 14. Incident initial positions and drifting buoy beginning positions.

drifter trajectories from outer ocean moving to eastern ocean of Taiwan for verification. The result showed that SAR areas of three incidents covered the target found in a short period of time (another two incidents were supposed to be consistent but unable to verify). Of the other five failures, one was too close to coasts where the current field is hard to simulated by larger grid size, three were at the southeastern and southern current fields where the numerical model had trouble to determine, and one was at the Penghu area.

Regarding ten drifters at Green Island, three's SAR area did not cover the drifting trajectories due to the deviation at the initial vector, three covered the drifter trajectories for three days, one for two days. The other three drifted slowly due to small initial vector despite one to two days of trajectories were matched. As to the six cases of drifters from outer seas to coastal waters of eastern Taiwan, only one covered the drifter trajectory for three days, and the rest were affected by the numerical model boundary conditions and pointed toward to land. Figure 14 shows the incident initial positions and the beginning positions of drifting buoys which deployed for verification.

The calculation drifter trajectories of the same cases as above but with consideration of leeway showed that the trajectories of four incidents were close to where they were found in a short period of time (two were consistent with the method used by CGA and unable to verify). As for the other four failures, one was found close to the shore and three were located at southeastern and southern areas of Taiwan with wrong flow patterns in numerical model. With regard to ten drifters at Green Island, three drifters moved to the north, five followed roughly with the real trajectories, one drifted around northwestern of Taiwan and toward north which was inconsistent with the buoy drifting toward to the right, and one drifted

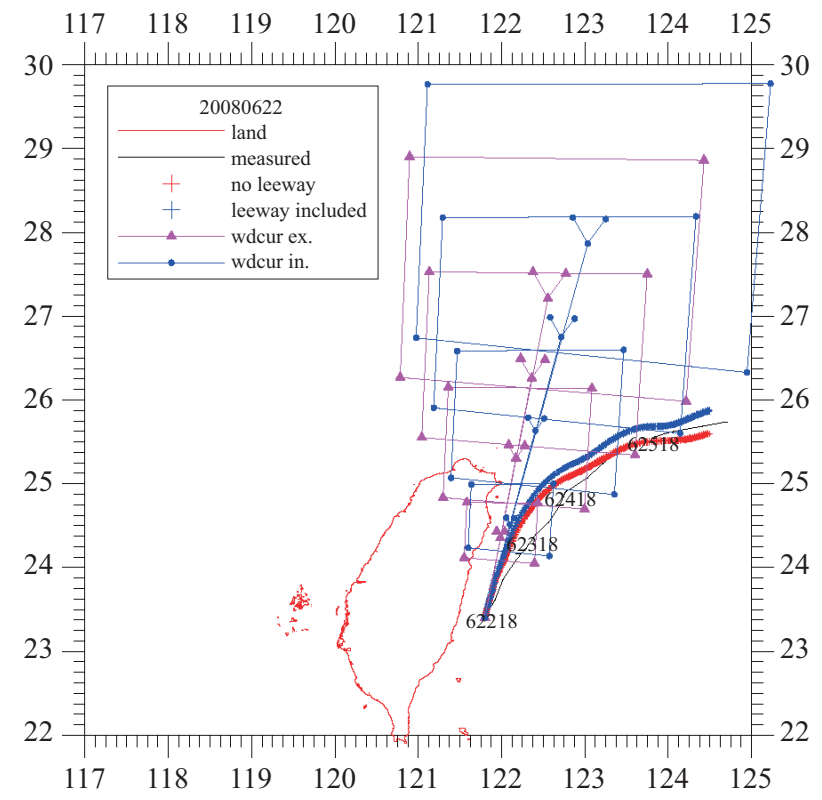

Fig. 15. Comparison of drift trajectory, calculation drifter trajectory and SAR areas in different time.
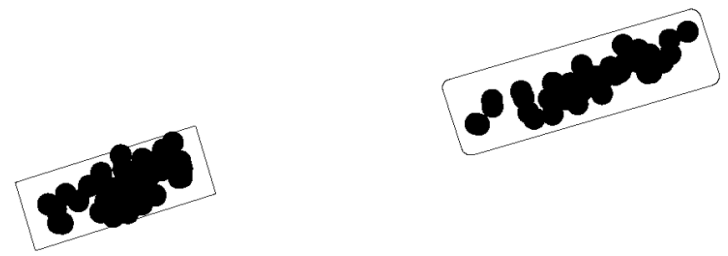

Fig. 16. Use of Monte Carlo method for SAD.

slowly but with the same trend. Regarding the six cases of drifters from outer seas to coastal waters of eastern Taiwan, two approximately matched the drifting trajectory, the two calculated drifter trajectories without leeway were consistent with the drifter trajectory, one drifted toward north, and the other followed the trajectory at first but later drifted off and turned around.

From the above analyses, it is suggested that the calculation drifting trajectories depends heavily on the accuracy of current fields regardless the limits of SAD from CGA (as shown in Fig. 15) and the trend of results are better than the SAD of CGA. Obviously, it could be better than the method provided by CGA if we start with the calculation of drifting trajectory and then go to the development of SAD mechanism (e.g. combination of the drifting trajectories with leeway and SAD proposed by CGA, or considering the use of Monte Carlo calculation). However, tracking algorithms using Monte Carlo method already becomes the mainstream of SAR (as shown in Fig. 16). It seems to be the most straightforward one by modeling thousands of possible outcomes.

\section{Drift Trajectory and SAD Display System}

The user-friendly user interface of system is developed by 


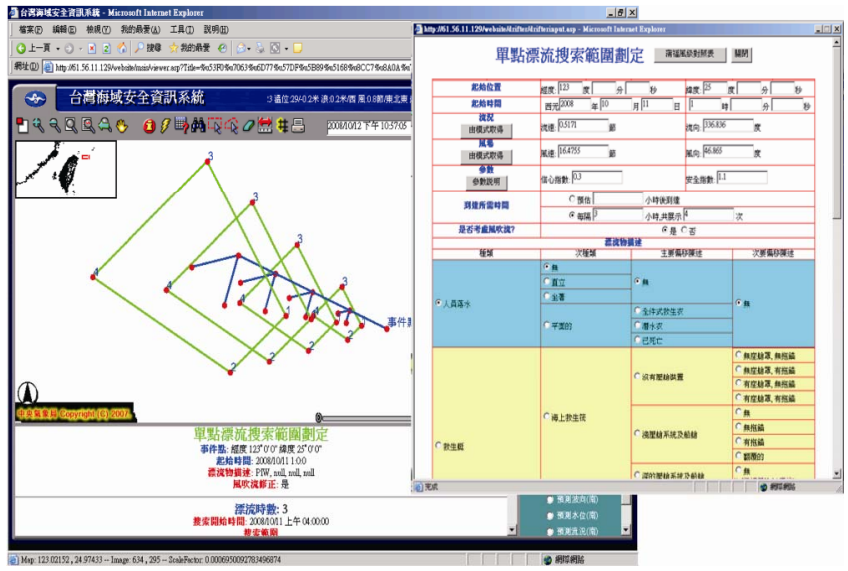

Fig. 17. SAD user interface and SAR areas display.

using JavaScript, ASP and HTML internet programs, combined with the ArcIMS program module to implement real time geographic information display mechanism. Users are not only allowed to mark the start position with ease, but also highlight the SAR area or drifter trajectories.

There are three options of drifter analysis: "single-point drifting SAD", "multi-point drifting SAD" and "drifter trajectory calculated by numerical model." The user must input initial location, date and time, ocean current, wind, confidence and safety parameters, rescue arrival time etc. For calculation of drifter trajectory, time interval, number of drift particles and radius of distribution have to be input in addition to particle location and initial date \& time as shown in Figs. 17, 18.

\section{GLOBAL SATELLITE TRACKING WEB GEOGRAPHICAL INFORMATION SYSTEM}

In order to make the locations of the near shore ships and sailing data could be easily convey through wireless communication and import to databases, the Global Satellite Tracking Web GIS was established in this study. Users can obtain the ships locations and real time marine data in computer through internet browser. The main purpose of the service is to offer fleet management, marine search and rescue operation, coastal engineering planning, and marine resources investigation usages. The system was to utilize HS communication scheme, Bluetooth transmission, and advanced ultra mobile PC to transmit ship observation data and GPS position back to the control center. The project tracked two ships simultaneously and obtained their observation data. One of the ships transmits back wind data. The on-board system can receive marine safety information as well. This tracking and data collection system is emphasized more on the position and the data obtaining from the vessel and not specifically for serving the full necessity of navigating a vessel, thus, the Location-Based Service (LBS) idea was not elaborate in this study. Although the two-way data communication can deliver nearby weather and sea state information as well as the marine GIS informa-

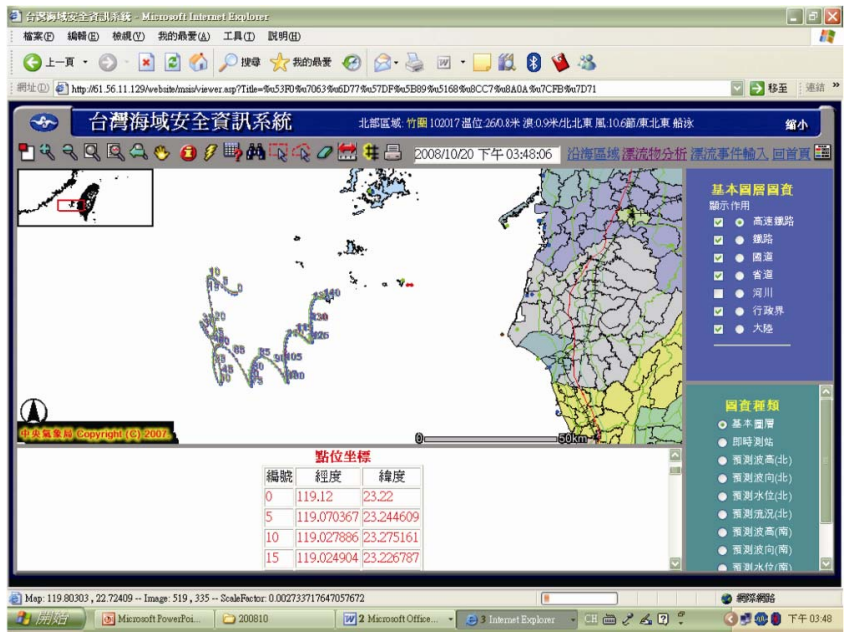

Fig. 18. Display of calculated drifter trajectories.

tion to the vessel, this function is still in developing and will be the study item in the future stage.

\section{Structure and Components}

At the beginning, the system used General Packet Radio Service (GPRS) communication to transmit Global Positioning Satellites data along with the instrument measured weather data to the onshore station. At 2007, the communication method was changed to use $3 \mathrm{G}$ wireless communication, and uses the newest technology - HSDPA to transmit the data and added the transmission of video images of the bow of the ship. The structure of the system is shown in Fig. 19.

Figure 20 shows the first set of the on-board system (GPRS version), which includes the major parts of Ultra Mobile Personal Computer (UMPC), GPRS modem, USB converter, wind gauge, hygrometer, thermometer, and GPS receiver with Bluetooth communication, etc. Figure 3 shows the second set of the on-board system (GPRS version), which includes the major parts of Ultra Mobile Personal Computer (UMPC), GPRS modem, USB converter, hygrometer, thermometer, and GPS receiver with Bluetooth communication, etc.

\section{Test and Application Results}

On November 27, 2006, two vessels were tracked at the same time by the system successfully at the estuary of Tanshui River in the northern part of Taiwan. One of the vessels transmitted back wind speed and direction data when conducted the test. Figure 21 shows the screen capture results of the web GIS system. One can see that Ship No. 1 (SH01) was heading to the left side of the River while Ship No. 2 (SH02) almost reached the pier of Tanshui Fisherman Wharf. The ship observation data and the positions of the both vessels along with the time of the acquisition were displayed at the bottom of the window.

\section{Offshore Island Test}

A three-month-long test was conducted for the system dur- 


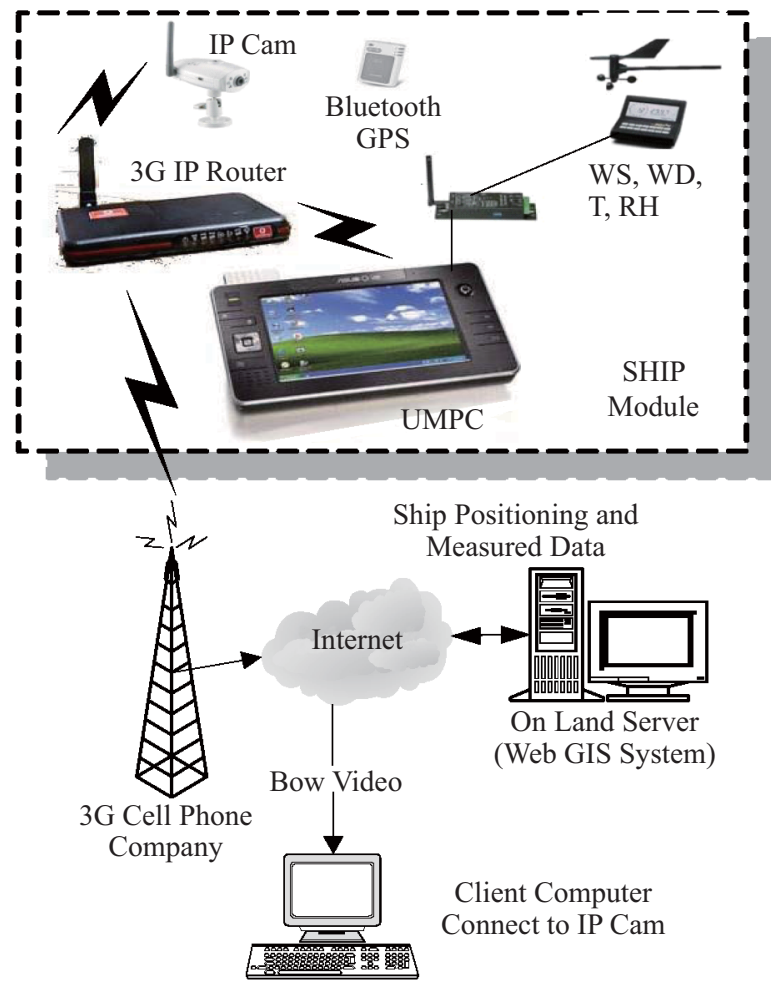

Fig. 19. Global Satellite Tracking Web GIS System structure.

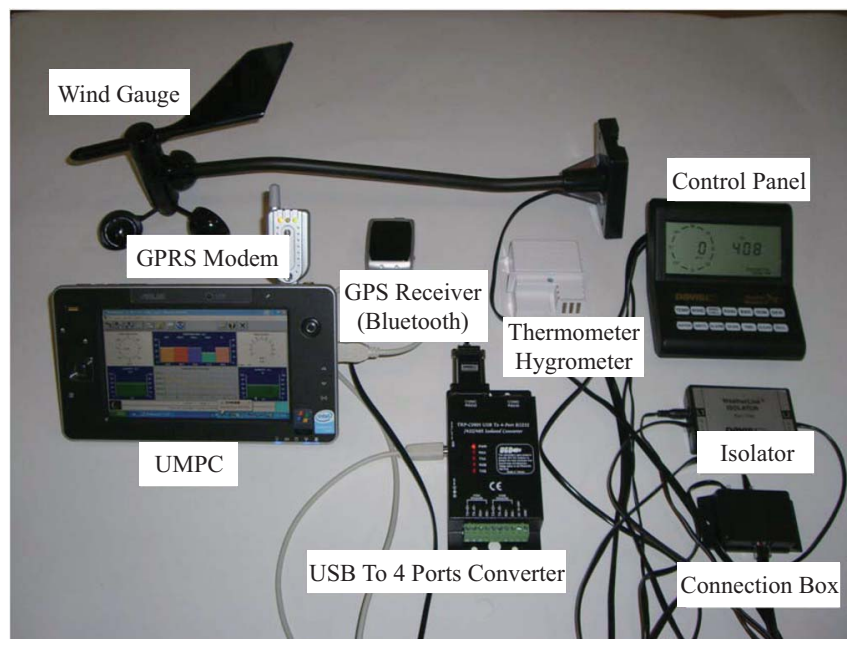

Fig. 20. Global Satellite Tracking Web GIS System on board components of the first set (previous version).

ing the Establishment of Marine Information e-Service System study period. On-board components were installed on the ferryboat between Donggang Township and Liouciou Township (offshore island) at the southern part of Taiwan on August 19, 2008 and moved to another ferryboat on September 26, 2008. Since then the system was constantly tested until the end of 2008. The screen captures of some of the tests were shown from Fig. 9 through 12. Figure 22 shows the ferryboat (SH02) arrived Donggang ferryboat dock and the Coast Guard

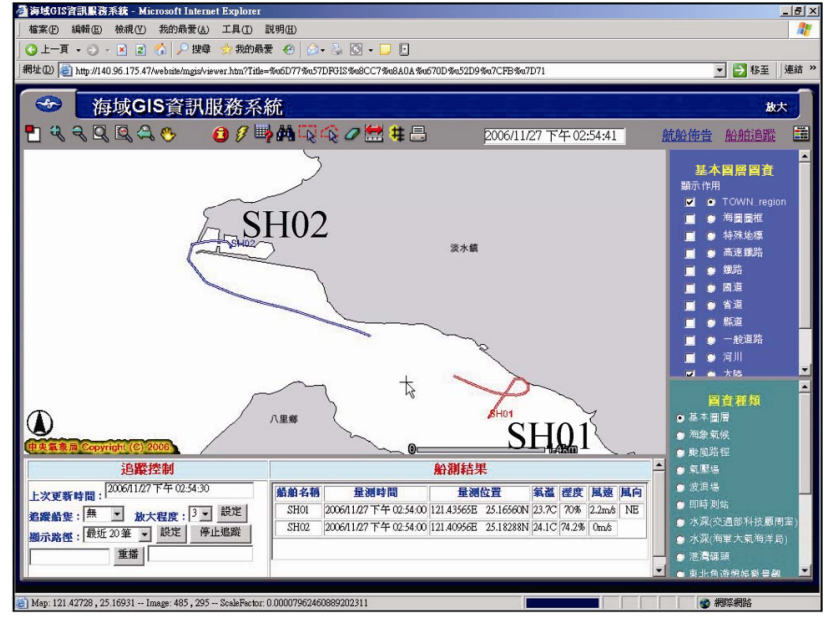

Fig. 21. Watching the Web GIS based tracking system remotely from an Internet browser. The $23.7^{\circ} \mathrm{C}, 70 \%$ relative humidity, and $\mathrm{NE}$ wind of $2.2 \mathrm{~m} / \mathrm{s}$ were observed on the first ship and $24.1^{\circ} \mathrm{C}$, 74.2\% relative humidity were observed on the second ship.

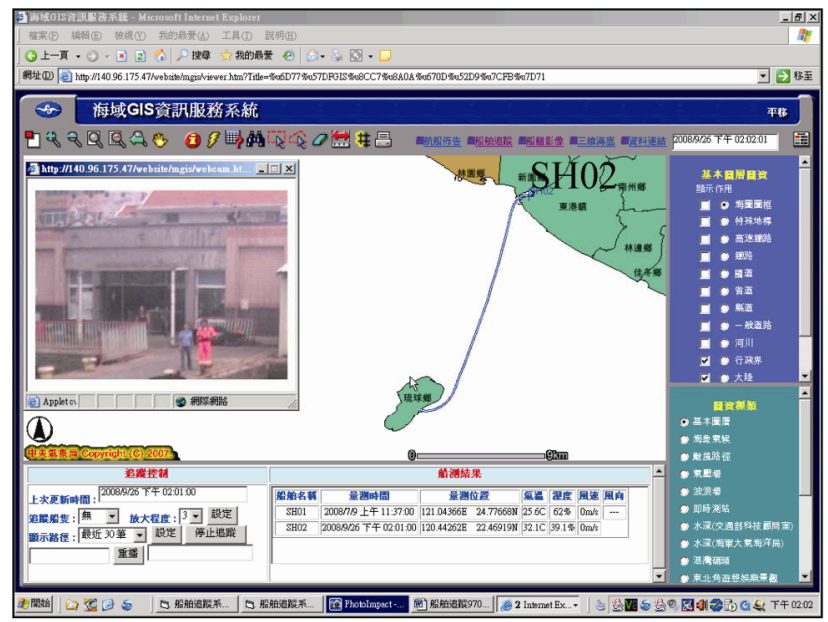

Fig. 22. Ferryboat arrived Donggang ferryboat dock and ready to be docked.

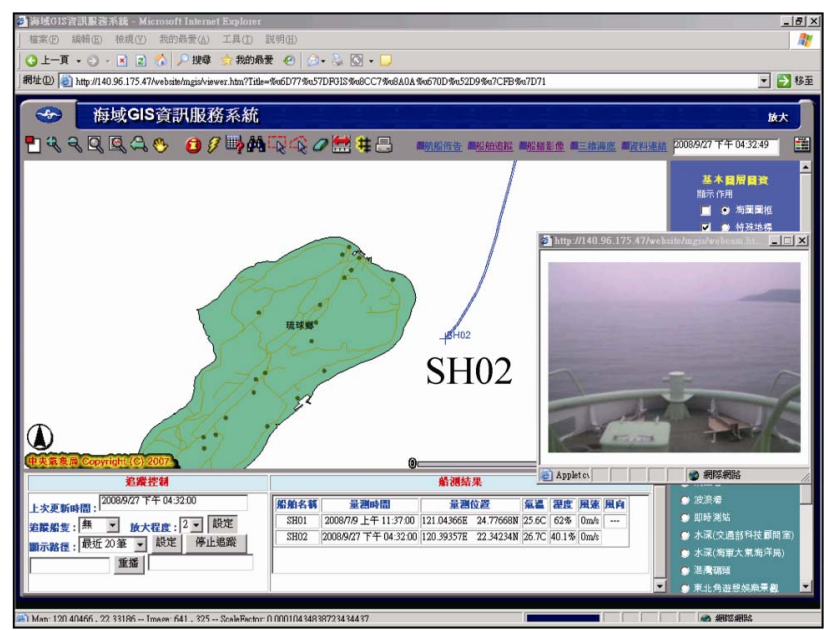

Fig. 23. Ferryboat approached Liouciou Township. 


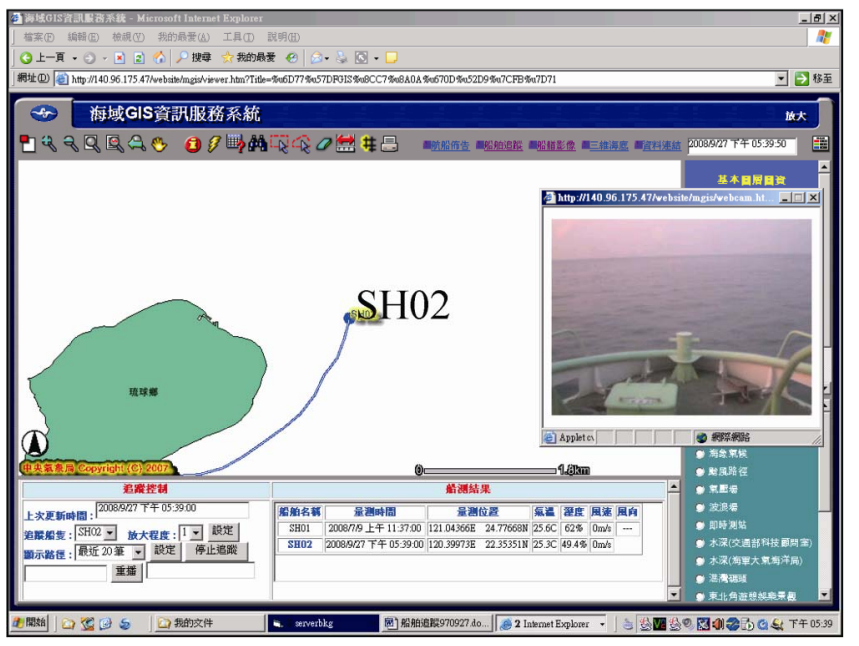

Fig. 24. The ferryboat was shown in the Tracking Mode.

personnel were standby to dock the vessel. Figure 23 shows the ferryboat (SH02) approached Liouciou Township and the IP cam could clearly show the landform of Liouciou Township. Figure 24 shows the ferryboat was leaving Liouciou Township and head toward Donggang. The system at that time was in the Tracking Mode that always shows the ferryboat's position in the center of the map window, and the name of the ferryboat was highlighted in the data window.

\section{CONCLUSION}

Taiwan, located between the tropics and the subtropics, lies on the border between the largest land mass and the largest ocean in the world, the marine and atmospheric environments here are complex and sensitive. With the increasing influence of global warming, the amounts of typhoon attacked Taiwan were increased apparently. Therefore, marine data analysis plays an important role on disasters protection at near shore area. The purpose of this study is to establish the multifunction querying system by applying e-technology on marine data.

Unified Modeling Language (UML) is a kind of subject's tendency technology tool which adopted in this study. Marine data were transferred into different types of management information according to the performance of spatial analysis in geographical information system which could offer the reference of development in GIS application.

Due to the influences of topography, the results of cluster analysis show the data records from neighbor stations would not be always fall into the same cluster. It implied the sea states from neighbor sea areas may be non-homogeneous. It is revealed Gamma distribution function is suitable for describing the probability distribution of the wave height records in most of the sea areas over Taiwan waters. On the other hand, Weibull distribution function is suitable for describing the probability distribution of the surge records in most of the sea areas.
From the marine drifter track analyses, it is suggested that the calculation drifting trajectories depends heavily on the accuracy of current fields regardless the limits of SAD from CGA, and the trend of results are better than the SAD of CGA. Obviously, it could be better than the method provided by CGA if we start with the calculation of drifting trajectory and then go to the development of SAD mechanism.

A near-shore inexpensive vessel tracking and data observation system using GPS, GIS, and 3G wireless communication technologies was established and tested in this study. Advantages of Global Satellite Tracking Web GIS could make the locations of the near shore ships and sailing data can be easily convey through wireless communication and import to databases.

\section{ACKNOWLEDGMENTS}

This research was supported by the TAIWAN Central Weather Bureau. Grateful appreciation is expressed to their support: MOTC-CWB-98-O-02.

\section{REFERENCES}

1. Aerf, H., "Stirring by chaotic advection," Journal of Fluid Mechanics, Vol. 143, pp. 1-21 (1984).

2. Aerf, H., "Chaotic advection of fluid particles," Philosophical Transactions: Physical Sciences and Engineering, Vol. 333, Issue 1631, pp. 273 288 (1990)

3. Allen, A. A. and Plourde, J. V., "Review of leeway: Field experiments and implementation," Report No. CG-D-08-99, U.S. Coast guard research and development center (1999).

4. Chien, L. K., Feng, T. S., Yen, C. C., and Lee, B. C., "Establishment of the marine GIS information service system in Taiwan coastal area," Proceedings of the 19th International Offshore and Polar Engineering Conference, Osaka, Japan, pp. 298-304 (2009).

5. Chinese Ocean Underwater Technology Association, "The planning of database in marine motoring and ocean environment," Traffic Military Project (in Chinese) (1994).

6. Chinese Ocean Underwater Technology Association, "The establishment of survey in marine water depth and undersea environment," Traffic Military Project (in Chinese) (1998).

7. Chinese Ocean Underwater Technology Association, "The establishment of coastal tourism resource and disaster protection(1/2)," Traffic Military Project (in Chinese) (2003).

8. Industrial Technology Research Institute, "The technical report of coastal information system in Wai-San-Ding area," Taiwan Economical Military Project (1993).

9. Kao, C. C., Chuang Laurence Z. H., Lin, Y. P., and Lee, B. C., "An introduction to the operational data buoy system in Taiwan," Proceedings of the International MEDCOAST Conference on Wind and Wave Climate of the Mediterranean \& the Black Sea, Cape Town, South Africa, pp. 33-39 (1999).

10. Lee, B. C., Jao, K. C., Cheng, C. W., and Wu, L. C., "Preliminary study on statistical characteristics of waves and surges over taiwan waters," Proceedings of the 19th International Offshore and Polar Engineering Conference, Osaka, Japan, pp. 1230-1235 (2009).

11. Lee, B. C., Wu, L. C., Doong, D. J., and Kao, C. C., "Seasonal variations of wind and wave data over Taiwan waters," Marine Geophysical Researches, Vol. 28, No. 3, pp. 183-190 (2007).

12. Lin, J. P., "The study of establishment of GIS in Ken-Ding national park," 4th Coral Reef Biology Conference, Ken-Ding (1996). 
13. Liu, C. C., Lin, C. Y., Huang, G. S., Chen, Y. G., Tseng, C. D., and Chen, S. C., "The establishment and querying of GIS application in Taiwan," Fishery. Monthly Fishery Development, Vol. 166, pp. 16-25 (2000).

14. Liu, D., Jiang, J., and Wang, C., "Extreme wave prediction in markov chain condition," Proceedings of the $8^{\text {th }}$ International Offshore and Polar Engineering Conference, Montreal Canada, pp. 84-90 (1998).

15. Paldor, N., Dvorkin, Y., Mariano, A. J., Özgökmen, T., and Ryan, E. H., "A practical, hybrid model for predicting the trajectories of near-surface ocean drifters," Journal of Atmosphere Oceanic Technology, Vol. 21, pp. 1246-1258 (2004).

16. Samelson, R. M., "Chaotic transport by mesoscale motions," in: Adler, R. J., Muller, P., and Rozovskii, B. L., (Eds.), Stochastic Modeling in Physical Oceanography, Birkhauser, Boston, p. 423 (1996).

17. Shie, S. W. and Lee, S. H., "The establishment of GIS database in An-
Ping harbor and nearshore area," Traffic Military Harbor Research Center Project (1999).

18. Shie, S. W. and Lee, Z. P., "The application of GPS and GIS in coastal fishery," Taiwan Fishery Conference, Kaohsiung (1993).

19. Tsai, C. P., Chang, L., and Shen, J. N., "Neural network for wave forecasting among multi-stations," Ocean Engineering, Vol. 29, pp. 1683-1695 (2002).

20. Yen, C. C., "The planning system of spatial exploitation in Chai-Yi coast," 18th Ocean Engineering Conference, Kaohsiung, pp. 857-865 (1996)

21. Yen, C. C., Chien, L. K., Feng, T. S., and Lee, B. C., "Establishment and application of global satellite tracking web geographical information sstem," Proceedings of the 19th International Offshore and Polar Engineering Conference, Osaka, Japan, pp. 305-310 (2009). 